Z.-H. Jin, D. Yun, Y.-X. Liu, Z.-Y. Tian, S. Richter, M. Braun-Unkhoff, C. Naumann, J.-Z. Yang, An experimental investigation of furfural oxidation and the development of a comprehensive combustion model, Combust. Flame 226 (2021) 200-210.

The original publication is available at www.elsevier.com http://dx.doi.org/10.1016/j.combustflame.2020.12.015.

(C) <year>. This manuscript version is made available under the CC-BY-NC-ND 4.0 license http://creativecommons.org/licenses/by-nc-nd/4.0/ 


\title{
An experimental investigation of furfural oxidation and the development of a comprehensive combustion model
}

\author{
Zhi-Hao Jin ${ }^{\mathrm{a}, \mathrm{b}, 1}$, Dan Yu ${ }^{\mathrm{a}, 1}$, Yue-Xi Liu ${ }^{\mathrm{a}, \mathrm{b}}$, Zhen-Yu Tian ${ }^{\mathrm{a}, \mathrm{b}, *}$, \\ Sandra Richter ${ }^{\mathrm{c}}$, Marina Braun-Unkhoff ${ }^{\mathrm{c}}, *$, Clemens Naumann ${ }^{\mathrm{c}}$, Jiu-Zhong Yang ${ }^{\mathrm{d}}$ \\ ${ }^{a}$ Institute of Engineering Thermophysics, Chinese Academy of Sciences, Beijing 100190, China; ${ }^{b}$ University of Chinese \\ Academy of Sciences, Beijing 100049, China; ' German Aerospace Center (DLR), Institute of Combustion Technology, \\ 70569 Stuttgart, Germany; ${ }^{d}$ National Synchrotron Radiation Laboratory, University of Science and Technology of \\ China, Hefei, Anhui 230029, China; ${ }^{1}$ Both contributed equally; *Corresponding authors: tianzhenyu@iet.cn, \\ Marina.Braun-Unkhoff@dlr.de
}

Abstract: The oxidation of furfural has been studied experimentally in a jet-stirred reactor (JSR) under fuel-lean $(\Phi=0.4)$ and fuel-rich conditions $(\Phi=2.0)$ in the temperature range of $650-950 \mathrm{~K}$; in addition, laminar burning velocity data have been measured at $T=473 \mathrm{~K}$ and $p=1$ bar within a wide fuel-air range. From the JSR experiments, 13 species profiles have been identified and quantified by GC-MS and GC. A detailed kinetic reaction model involving 382 species and 2262 reactions was developed by exploiting the experimental data base provided within the present work as well as experimental data reported in literature. The rate coefficients of reactions of $\mathrm{H}$ abstraction, $\mathrm{H}$ addition as well as of decomposition of furfural were calculated by quantum chemical methods at CBS-QB3 level. A general agreement was achieved when simulating the experimental data. Rate of production analysis as well as sensitivity analysis were performed to get a deeper insight into the combustion of furfural, e.g. for the jet-stirred reactor data at around 50\% fuel conversion, as well as sensitivity analysis of laminar flame speeds conducted for a fuel-air ratio $\Phi=0.9,1.2$, and 1.6. According to the analysis, the main consumption pathways of furfural oxidation were identified as $\mathrm{H}$ abstraction reactions of the $\mathrm{R}-\mathrm{CHO}$ (aldehyde) group by $\mathrm{H}, \mathrm{OH}, \mathrm{O}$, and $\mathrm{HO}_{2}$ to produce a furfural radical (furfural6). At pyrolysis condition, the dominant pathways within the furfural decay were found to occur via ring opening by splitting the $\mathrm{C}-\mathrm{O}$ bond followed by isomerization to form $\alpha$-pyrone $\left(\mathrm{C}_{5} \mathrm{H}_{4} \mathrm{O}_{2}\right)$. Even more, the measured laminar flame speed data are well reproduced by the reaction model developed within the present work. The experimental data base as well as the developed reaction model will assist 
and contribute to a more detailed understanding of the combustion behavior of furfural and of furan derivatives as well.

Key words: Furfural combustion; Kinetic reaction mechanism Quantum mechanical calculation; Jet-stirred reactor; Laminar flame speed. 


\section{Introduction}

Nowadays, new energy sources are urgently needed because of the worldwide energy shortage and environmental pollution caused by the use of fossil fuels. Biofuels in general, such as ethanol or biodiesel $[1,2]$, have attracted much attention due to their renewability (enabling a lower $\mathrm{CO}_{2}$ footprint) and large storage capacity, besides further benefits to the environment by a reduced emission pattern, e.g. lower amounts of soot particles (in the case of oxygenated fuels). In this context, furan derivatives (see Fig. 1), produced from non-edible feedstocks, especially 2-methylfuran (MF) and 2,5-dimethylfuran (DMF), were demonstrated to have additional benefits as next generation alternative fuels due to their significant advantages over traditional biofuels [3-7]. For instance, DMF-diesel blends produce less soot compared to blends of diesel and n-butanol $[3,5]$. Furthermore, the octane number of DMF is higher than that of ethanol [8]. Also, the heating values of furan, MF, and DMF are larger than that of ethanol [4] and thus, similar to that of gasoline. Sudholt et al. [9] investigated derived cetane numbers $(\mathrm{DCN})$ of several furan derivatives, with furan, MF, DMF, among other, to characterize their ignition behavior. According to DCN and bond dissociation energies (BDE) at CBS-QB3 level, they found that the ignition behavior of the furan derivatives is governed by the ring structure, while the chain structure has a negligible effect.

Furfural is generally produced from C5 sugars (such as arabinose and xylose) being constituents of hemicellulose derivative [10]. Furfural is a feedstock of several furan derivatives $[4,8]$ and thus, an important intermediate within furan derivatives oxidation [11]. Moreover, furfural, as a non-petroleum based chemical feedstock, is also a precursor for the production of valerate esters, pentanols, and 1octanol as well as various $\mathrm{C}_{10}-\mathrm{C}_{15}$ coupling products [12-14]. Furfural also shows some interesting combustion properties. Within furfural combustion, a reduced production of soot was reported compared to hydrocarbon fuels [15]. Blending furfural in the tri-propylene glycol mono-methyl ether $\left(\mathrm{C}_{10} \mathrm{H}_{22} \mathrm{O}_{4}\right)$, being a possible fuel additive, was shown to enhance the ignition reactivity compared to 
blending with furan or methyl substituted furans [16]. Therefore, studies focusing on the oxidation process at lean conditions are necessary for studying the combustion properties of furfural as an additive to diesel. Furthermore, furfural is also an important compound within the thermal conversion process of biomass [17-21]. Pyrolysis experiments as well as those at fuel-rich conditions are needed to investigate its conversion pathways. Hence, research on furfural combustion is meaningful for its efficient usage as well as to understand more comprehensively the combustion of furan derivatives and to assess better biomass pyrolysis.
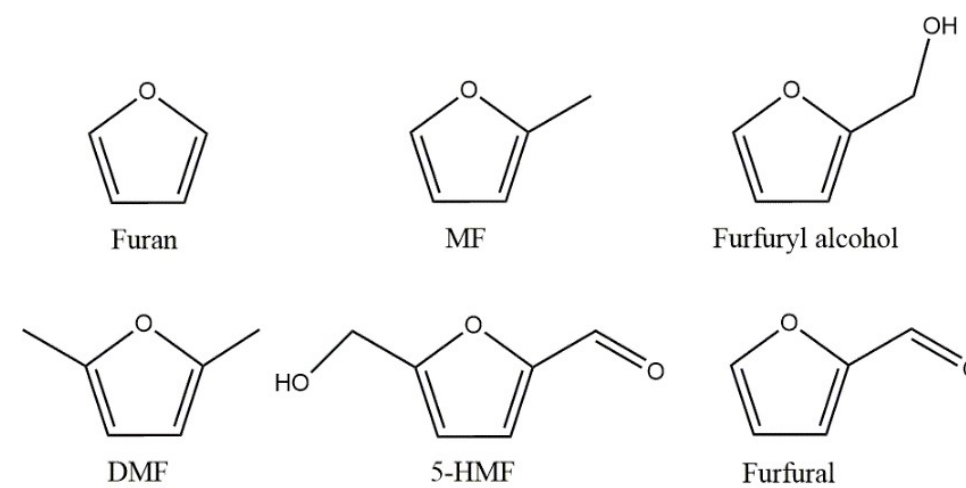

Fig. 1 Chemical structures of furfural and of major furan derivatives: furan, 2-methylfuran (MF), furfuryl alcohol, 2,5-dimethylfuran (DMF), 5-hydroxymethylfurfural (5-HMF), and furfural.

Some earlier work has been performed to identify the major furfural consumption pathways, through theoretical calculation and experiments, as summarized in Table 1. Zhao et al. [22] reported that the furfural oxidation which they studied at ambient pressure was initiated via hydroxyl radicals reactions by using quantum chemistry and kinetic calculations. The furfural oxidation was also investigated by Thorton et al. [23] in a JSR combined with gas chromatography (GC), within temperatures between 1000-1300 K at atmospheric pressure. They identified as the main fuel consumption pathway the $\mathrm{H}$ abstraction of furfural forming a furfural radical which reacts further decomposing into a furan radical and $\mathrm{CO}$. Due to the lack of high-precision experimental measurements and quantum chemistry calculations, Thorton et al. [23] proposed a preliminary mechanism for furfural oxidation; however, 
no detailed kinetic model was provided. Vasiliou et al. [24] investigated the thermal decomposition of furfural in a heated micro tubular flow reactor within the temperature range of 1200-1800 K, at 75150 torr. They found that the ring-opening pathway has a lower energy barrier compared to the formation pathway of carbenic intermediates and proposed the initial fuel decomposition process to be an unimolecular decomposition reaction step: furfural $(+\mathrm{M})=$ furan $+\mathrm{CO}(+\mathrm{M})$. Vermeire et al. [25] studied the furfural pyrolysis at atmospheric pressure in a jet-stirred reactor (JSR) combined with GC and GC-mass spectrometry (GC-MS). The important intermediates $\alpha$-pyrone and furan were observed and quantified, besides others. Based on experimental results and the calculated potential energy surface of furfural initiation reactions, they concluded that furfural decomposes mainly through a ringopening isomerization step forming formylvinylketene (cis- $\mathrm{O}=\mathrm{C}=\mathrm{CH}-\mathrm{CH}=\mathrm{CH}-\mathrm{CH}=\mathrm{O}$ ). $\mathrm{Li}$ et al. [26] investigated the thermal decomposition of furfural in a flow tube reactor at 30 torr by synchrotron vacuum ultraviolet photoionization and mass spectrometry. Also, they calculated the $\mathrm{H}$ addition and $\mathrm{H}$ abstraction reactions via $\mathrm{H}$ radical at the CBS-QB3 level.

Table 1 Overview of earlier studies on furfural consumption pathways

\begin{tabular}{cccccc}
\hline Method & Reactor & Temperature / K & $\begin{array}{c}\text { Pressure / } \\
\text { Torr }\end{array}$ & $\boldsymbol{\Phi}$ & Ref. \\
Exp. & JSR & $1000-1300$ & 760 & $0.085-0.115$ & {$[23]$} \\
Cal. & - & 298 & 760 & - & {$[22]$} \\
Exp. & Quartz tube & Various temperatures & Not given & $\infty$ & {$[27]$} \\
Exp. & Flow reactor & $>1400$ & Very low & $\infty$ & {$[28]$} \\
Exp., Cal. & Micro tubular flow reactor & $1200-1800$ & $75-150$ & $\infty$ & {$[24]$} \\
Exp., Cal. & JSR & $900-1100$ & 760 & $\infty$ & {$[25]$} \\
Exp., Cal. & Flow reactor & $1023-1073$ & 30 & $\infty$ & {$[26]$} \\
\hline
\end{tabular}

Note: Exp and Cal refer to experiments and theoretical calculations, respectively. 
Although there are several studies available on furfural combustion as discussed above, none of them was dedicated to studying the detailed decomposition pathways of furfural. Thus, additional investigation on furfural is desirable to be able to predict more comprehensively its combustion behavior and to reveal its dominant reaction pathways by the construction of a comprehensive chemical-kinetic reaction model being validated by experimental data.

In the present work, furfural oxidation was investigated in a JSR at atmospheric pressure in the temperature range of 650-950 K, at two equivalence ratios $\Phi: 0.4$ (fuel-lean) and 2.0 (fuel-rich). Furthermore, the laminar burning velocity of furfural in air was measured over a $\Phi$-range from 0.6 to 1.8 at a preheat temperature of $T=473 \mathrm{~K}$ and at ambient pressure, $p=1 \mathrm{bar}$. Based on the experimental data, a comprehensive detailed chemical kinetic reaction model was developed to simulate the furfural oxidation (present work) and its pyrolysis (experimental data taken from Vermeire et al. [25]) as well as the laminar flame speed data (present work). Also, rate of production (ROP) and sensitivity analyses were used to identify the dominant consumption pathways of furfural. Furthermore, reaction rate expressions of major initiation reactions within furfural consumption have been determined by applying quantum chemical calculations, at CBS-QB3 level found to be appropriate for these types of fuels [2932].

\section{Experimental}

\subsection{Jet-stirred reactor experiment}

The oxidation of furfural was carried out in a jet-stirred reactor developed and constructed at Chinese Academy of Sciences (CAS). The experimental setup and procedure have been described in detail in previous studies $[33,34]$; hence, only a brief description is given here. The volume of the JSR is $64.3 \mathrm{~cm}^{3}$, its inlet diameter $50 \mathrm{~mm}$, respectively. For the experimental conditions applied in the present work, the average of the reaction time $(\tau)$ was around $1.50 \mathrm{~s}$; the total flow rate was $1000 \mathrm{sccm}$ 
(standard cubic centimeter per minute), with the flow rates of oxygen (99.999\% purity, Beiwen gas) of 12.5 and $62.5 \mathrm{sccm}$, corresponding to the fuel equivalence ratios $\Phi$ of 0.4 and 2.0 , respectively. The inlet mole concentration of furfural (purity $>99.0 \%$, Sinopharm) was $0.5 \%$. It was infused into a vaporization tank by a high-pressure infusion pump (FL2200, Fuli) and carried by argon (99.999\% purity, Beiwen gas) with a flow rate of $450 \mathrm{sccm}$. Finally, using a second argon flow the gas mixture is transported into the JSR. The flow rates of all gases were controlled by mass flow meters (Sevenstar, CS200) with an uncertainty of $\pm 1.0 \%$. In order to avoid a temperature gradient as well as the condensation of furfural (boiling point b.p. $=435 \mathrm{~K}$ ), the vaporization tank and all tubes were heated to $473 \mathrm{~K}$. A thermocouple type K (Huayangyide) with an uncertainty of $\pm 5 \mathrm{~K}$ was fixed in the center of the JSR in order to get the real inner JSR temperature.

The outlet species and their real-time mole fractions were identified and quantified by online GCMS (Agilent 7890B-5977A) and GC (Agilent 7890B), respectively. A Thermal Conductivity Detector (TCD) was used to detect $\mathrm{CO}, \mathrm{CO}_{2}$, and $\mathrm{CH}_{4}$ with the detection limit of $10.0 \mathrm{ppm}$. A Flame Ionization Detector (FID) combined with an $\mathrm{Al}_{2} \mathrm{O}_{3}-\mathrm{KCl}$ column and a HP-INNOWax column, respectively were used to detect the light hydrocarbons (methane, acetylene, ethylene, propene, and allene) and oxygenated species (acetaldehyde, acrolein, furan, furfural) within the detection limit of $0.1 \mathrm{ppm}$. The effective carbon number method as described in [35] was performed for the quantification of the newly detected species. The detailed quantification method is described in detail within the Supplemental Material (SM). Detection was repeated at least three times at each measured temperature. The estimated uncertainties, mainly resulting from the limited accuracy of the GC diagnostic method, were $\pm 5 \%$ for the major species and $\pm 15 \%$ for the minor intermediates. The carbon balances are closed within $10 \%$ at most conditions. It should be noted that the GC columns used in the present study did not allow to detect water and formaldehyde; hence, the hydrogen and oxygen balances cannot be calculated. 


\subsection{Measurement of the laminar burning velocity}

The laminar burning velocity $\left(S_{\mathrm{u}}\right)$ values were determined at a preheat temperature of $T=473 \mathrm{~K}$ and a pressure of $p=1$ bar within a fuel-air range of $\Phi$ between 0.6 and 1.8 by applying the cone angle method. Since the method and the burner have been used in previous studies where the experimental set-up is described in more detail (e.g., [36, 37]), here only a short description is given. First, furfural (99\% purity, Sigma-Aldrich) is vaporized at $468 \mathrm{~K}$ (b.p. = $435 \mathrm{~K}$ ), then mixed directly after vaporization with a preheated $(473 \mathrm{~K}) \mathrm{N}_{2}$-stream $(99.999 \%$, Linde) and adjusted to the set temperature of $T=473 \mathrm{~K}$. In a second mixing step, preheated (473 K) $\mathrm{O}_{2}(99.95 \%$, Linde) is added yielding the specific fuel-air mixture. For the determination of the cone angle $(\alpha)$, premixed conical shaped flames have been stabilized above a flame holder as shown in the sketch of Fig. 2. To enable a stable flame, a co-flow is used, either air for fuel-rich flames $(\Phi \geq 1.0)$ or a mixture of $5 \% \mathrm{CH}_{4}+5 \% \mathrm{H}_{2}+90 \% \mathrm{~N}_{2}$ for fuel-lean flames $(\Phi \leq 1.0)$. The cone angle detection was performed by recording pictures with a CCD-camera (Imager Intense, LaVision). Values of the laminar burning velocity $\left(S_{\mathrm{u}}\right)$ are calculated from the cone angle $(\alpha)$ of the flame and the gas velocity $\left(v_{u}\right)$ of the unburned fuel-air mixture according to Fig. 2 and Eq. (1) [38, 39]:

$$
S_{\mathrm{u}}=v_{\mathrm{u}} \cdot \sin \alpha
$$




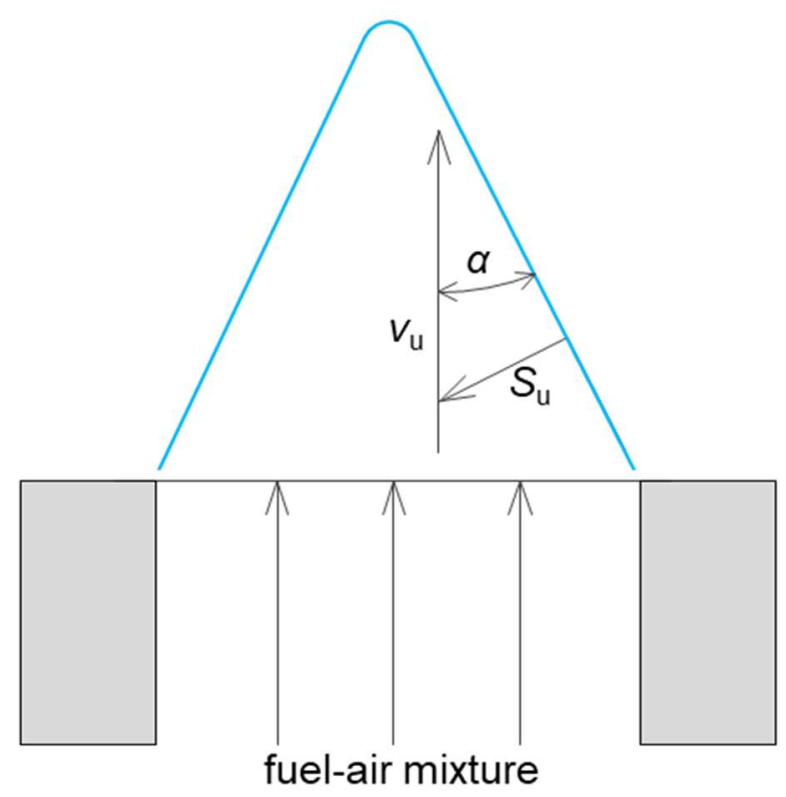

Fig. 2 Relation between laminar burning velocity $\left(S_{\mathrm{u}}\right)$, cone angle $(\alpha)$, and flow velocity $\left(v_{\mathrm{u}}\right)$ of a laminar premixed conical flame.

\section{Modeling}

The furfural oxidation studied within the JSR was simulated using the PSR code of Chemkin-Pro [40]. The laminar flame speed was calculated using Cantera [41] assuming a free flame and taking into account the multi-component diffusion model as well as thermo-diffusion. Mesh points were refined to achieve equal solution tolerance leading to about 130 mesh points. A detailed kinetic mechanism involving 382 species and 2262 reactions was newly developed (see also SM). This mechanism considers $\mathrm{H}$ abstraction, $\mathrm{H}$ and $\mathrm{OH}$ addition as well as unimolecular decomposition of furfural. The core model of this mechanism is based on our previous work [42] which has been validated against combustion data of acetylene, 1,2,4-trimethylbenzene, and n-propylbenzene [33, 34, 42]. Reaction rate coefficients of the furfural sub-model were obtained by CHEMRATE based on transition state theory or through analogy with molecules having similar structures as described from previous studies [11, 30, 43-45]. The mechanism for benzaldehyde [43, 45] was selected as analogy to determine the rate constants of $\mathrm{H}$ abstraction reactions by $\mathrm{O}, \mathrm{OH}$, and $\mathrm{HO}_{2}$ radicals at the aldehyde side within furfural. 
In addition, $\mathrm{H}$ abstraction reactions of furfural at the furan ring side referred to the furan mechanism $[44,46]$. Owing to the symmetrical structure of carbon atoms in furan, the values adopted within present model is half of that in their mechanism $[44,46]$. OH addition reactions are important consumption pathways of furan derivatives $[11,29]$. Reflecting the structure of furfural, the present model exploits MF kinetics [30] as reference to determine the rate expressions of the $\mathrm{OH}$ addition reactions of furfural. Moreover, within the frame of the present work, some oxidation routes of furfural such as $\mathrm{H}$ abstraction via $\mathrm{H}, \mathrm{O}_{2}$, and $\mathrm{CH}_{3}$ radicals, $\mathrm{H}$ addition as well as unimolecular dissociation reactions were calculated at the CBS-QB3 level as implemented in the Gaussian 16 package [47]. According to the results, the transition state of the calculated oxidation routes has a reasonable geometry and only one imaginary frequency; atomic displacement approaches the expected reaction coordinate. Detailed information of the furfural sub-model is displayed in Table S4. In addition, main decay pathways for important radicals such as furfural-6 and formylvinylketene (FVketene) were newly updated within the present work by CHEMRATE software or referring to mechanism of similar structure [11, 42, 48]. Further decomposition pathways of $\mathrm{H}$ as well as $\mathrm{OH}$ addition reactions were adopted from the MF model as developed by Somers et al. [30]; rate coefficients for the decay of furfural carbenic intermediates (e.g. F5carbene, F4carbene, and F3carbene) were estimated based on those of MF carbene [49]. Additionally, the furan sub-model from Tian et al. [44] was included in this work. Standard formation enthalpies of some important species (see SM section 2) have been obtained from the atomization method. Thermochemical properties as a function of temperature have been calculated using the CHEMRATE software [50] based on the CBS-QB3 optimized results. Hindered rotors have been taken into account and relaxed scans have been performed at the B3LYP/6-31G(p) level to determine the barrier of rotation. It is worth to mention that geometries of some species and transition states (especially involving unimolecular fission reactions) were adopted from literature reporting on calculations using Gaussian $09[25,26]$. Within the present work the above calculation results are optimized by Gaussian 16 [47] at the same calculation level, indicating no significant difference compared with 
previous calculation results. The structures of furfural and its derived intermediates are given in SM, section 2. In addition, corresponding names of the above molecules structures are also available in the same section of SM. Transport data of furfural and furfural-6, which are needed for the calculation of laminar flame speeds, were taken from literature [51, 52]. As for newly added other species in the furfural primary mechanism, their transport data were determined by analogy with molecules of similar structure as included within the MF mechanism [49]. All further transport data were taken from literature $[42,44]$. The primary reaction mechanism newly developed in the present work including its thermochemical and transport data is given within the SM.

The optimized structure of furfural is displayed in Fig. 3. In addition, BDE have been calculated in this work at CBS-QB3 level (see Table 2). The C-H bond of the aldehyde side (6C-H, see Fig. 3) has the lowest BDE according to Table 2. It indicates that the $6 \mathrm{C}-\mathrm{H}$ bond scission is easier to break than other $\mathrm{H}$ abstractions within furfural oxidation. $\mathrm{H}$ abstraction at the aldehyde side is the most reactive and their rate constants are higher than those at other positions within the oxidation process, as verified by $\mathrm{C}-\mathrm{H}$ BDEs.

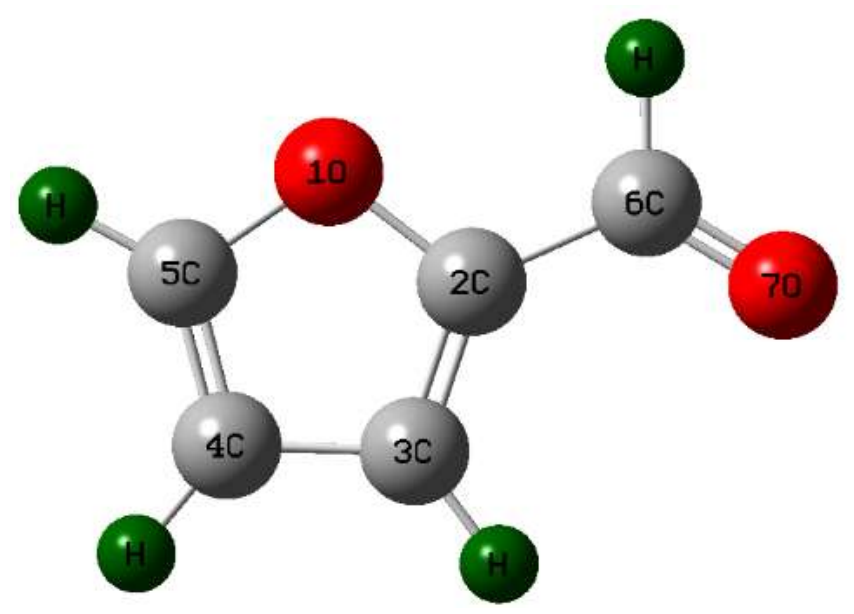

Fig. 3 Molecular structure of furfural.

Table $2 \mathrm{C}-\mathrm{H}$ bond dissociation energies (BDE) of furfural at 298.15 K calculated at CBS-QB3 level 
within the present work

\begin{tabular}{ccccc}
\hline Bond & D(6C-H) & D(3C-H) & D(4C-H) & D(5C-H) \\
\hline BDE $\left(\mathrm{kcal}^{\prime} \mathbf{m o l}^{-1}\right)$ & -90.6 & -120.6 & -119.7 & -119.2 \\
\hline
\end{tabular}

\section{Results and discussion}

In the oxidation process of furfural, the major species determined from the JSR experiments were $\mathrm{CO}$ and $\mathrm{CO}_{2}$. Several minor species including hydrocarbons (methane, acetylene, ethylene, propene, allene, and benzene) and oxygenated species (acetaldehyde, acrolein, and furan) were also measured. Therein, acetaldehyde $\left(\mathrm{CH}_{3} \mathrm{CHO}\right)$ and acrolein $\left(\mathrm{C}_{2} \mathrm{H}_{3} \mathrm{CHO}\right)$ were newly detected within the oxidation of furfural. The measured mole fractions of furfural and products as well as the predicted ones including sensitivity and rate of production (ROP) analyses using the reaction model developed within the present work are discussed in the sections 4.1 to 4.5 . The comparison between measured laminar burning velocities and calculated laminar flame speeds is presented in section 4.6 including its sensitivity analysis.

\subsection{Furfural consumption}

The determined consumption of furfural as a function of temperature is shown in Fig. 4. Here, the experimental data are reproduced reasonably by the present model. The furfural oxidation curves at the two equivalence ratios studied are close to each other. It should be noted that furan has a similar behavior, while MF and DMF show a wider gap between the two different equivalence ratios as reported by Tran et al. [11]. The results indicate that the CHO-group of the furan ring has a smaller influence on enlarging gaps with varying $\Phi$ of furan derivatives. Contrary, a $\mathrm{CH}_{3}$ group will increase the gap of the initial oxidation temperature with changing $\Phi[11]$. For the pyrolysis of furfural, the 
experimental data measured by Vermeire et al. [25] between 900 and $1100 \mathrm{~K}$ in JSR are also shown in Fig. 4. The inlet concentration of furfural is $0.5 \%$; helium was used as carrier gas within pyrolysis experiments. When checking the MF decomposition pathway [53], it was found that MF mainly decays via $\mathrm{H}$ migration to produce the respective cyclic carbenes shown in Fig. 5. Although the reaction rate constants of the carbene formation pathways of furfural and of MF are at the same order of magnitude, furfural has a lower initial reaction temperature than MF [53] at atmospheric pressure. Gaussian calculation results [25] indicate that the ring opening of furfural plays an important role in the lower temperature range. Most of furfural decompose by ring opening as a result of $\mathrm{C}-\mathrm{O}$ bond breakage (reaction: furfural $=$ FVketene), and then isomerizing to form $\alpha$-pyrone (reaction: FVketene $=\alpha$ pyrone).
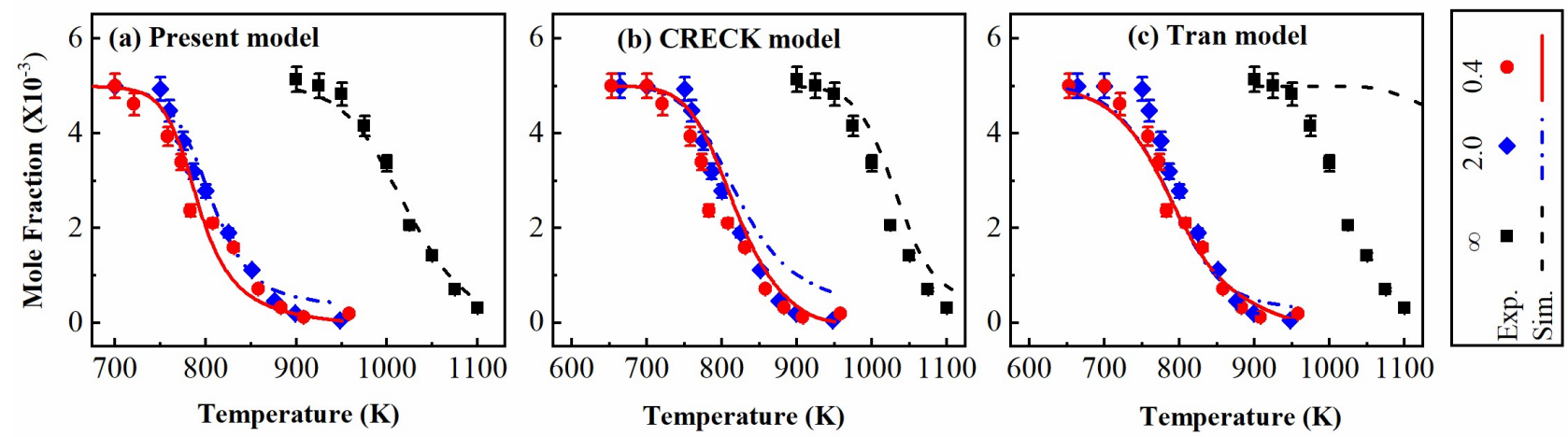

Fig. 4 Measured (symbols) and predicted (curves) mole fraction profiles of furfural. The oxidation data were measured in this work; the pyrolysis data were taken from Vermeire et al. [25]. Simulations were performed using the furfural model developed within the present work ( $\mathrm{a}-\mathrm{left})$ as well as the models from the CRECK modeling group [52] (b - middle) and Tran et al. [11] (c - right).
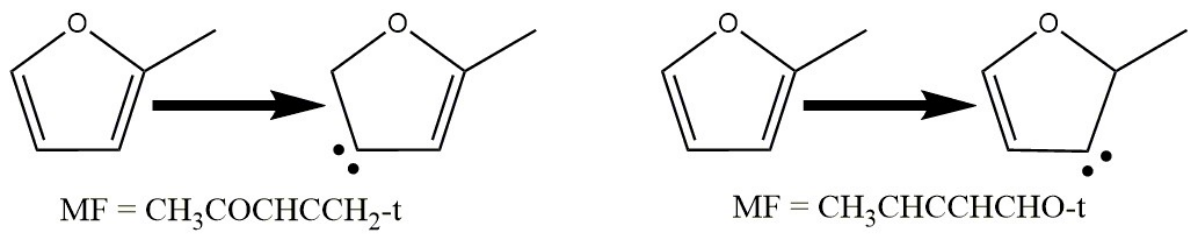

Fig. 5 The main initial decomposition paths for MF according to literature [29, 53]. 
In addition to the present model, Fig. 4 also displays simulated results using two reaction models from literature [11, 52]. The CRECK model [52] is built up by combining detailed kinetics as well as exploiting the lumping approach and is often used to simulate flame speeds of hydrocarbon and oxygenated fuels. Here, a lumped furfural sub-mechanism is included. In general, the results obtained with the CRECK model are in good agreement with the pyrolysis data (from Vermeire et al. [25]) and for fuel-lean conditions (present work) whereas the furfural consumption at fuel-rich conditions (present work) is underpredicted considerably, in particular for temperatures higher than about $800 \mathrm{~K}$. Simulation results for further intermediates using the CRECK model can be found in SM (section 5). The Tran model overpredicts furfural oxidation and shows somehow unsatisfying simulation results for the pyrolysis data, which results most probably from only $\mathrm{H}$ abstraction reactions having been involved in their furfural sub-mechanism. Note that the model by Tran et al. [11] has been developed and used primarily to simulate species profiles of furan, MF, and DMF, but not of furfural. For these reasons, the Tran et al. model was found to reveal a poor performance for other oxidation and pyrolysis products. So, further simulations using the Tran et al. model were not done within the present study.

\section{2 $\mathrm{CO}_{2}$ and $\mathrm{CO}$ formation}

Figure 6 shows the comparison between experimentally determined and predicted mole fraction profiles of $\mathrm{CO}_{2}$ as well as of $\mathrm{CO}$. Again, the experimental pyrolysis data are taken from Vermeire et al. [25]. The $\mathrm{CO}_{2}$ mole fraction increases with increasing temperature at fuel-lean $(\Phi=0.4)$ and at fuelrich $(\Phi=2.0)$ conditions. At temperatures above $800 \mathrm{~K}$, the $\mathrm{CO}_{2}$ mole fraction at lean condition rises stronger than at fuel-rich and pyrolysis conditions due to the oxygen excess at equivalence ratios $\Phi<1.0$. The considerably favored production of $\mathrm{CO}_{2}$ at fuel-lean condition and at higher temperatures leads to a peak-shaped profile of the CO mole fraction, with a peak value of about $1.6 \times 10^{-2}$ at $875 \mathrm{~K}$, 
and a sharp decrease of the $\mathrm{CO}$ mole fraction, since $\mathrm{CO}$ is converted to $\mathrm{CO}_{2}$ at temperatures above $900 \mathrm{~K}$. At fuel-rich condition, the CO mole fraction increases as temperature increases. For pyrolysis, CO appears late $(\mathrm{T}>1000 \mathrm{~K})$, and its amount is lower than that within oxidation while there is nearly no $\mathrm{CO}_{2}$ detected (within pyrolysis). This is caused by the fact that no oxygen is available and hence, more carbon is converted into light hydrocarbons (see section 4.3). The experimentally determined progression of the $\mathrm{CO}_{2}$ and $\mathrm{CO}$ mole fraction profiles is satisfactory predicted by the new reaction mechanism developed within this work.
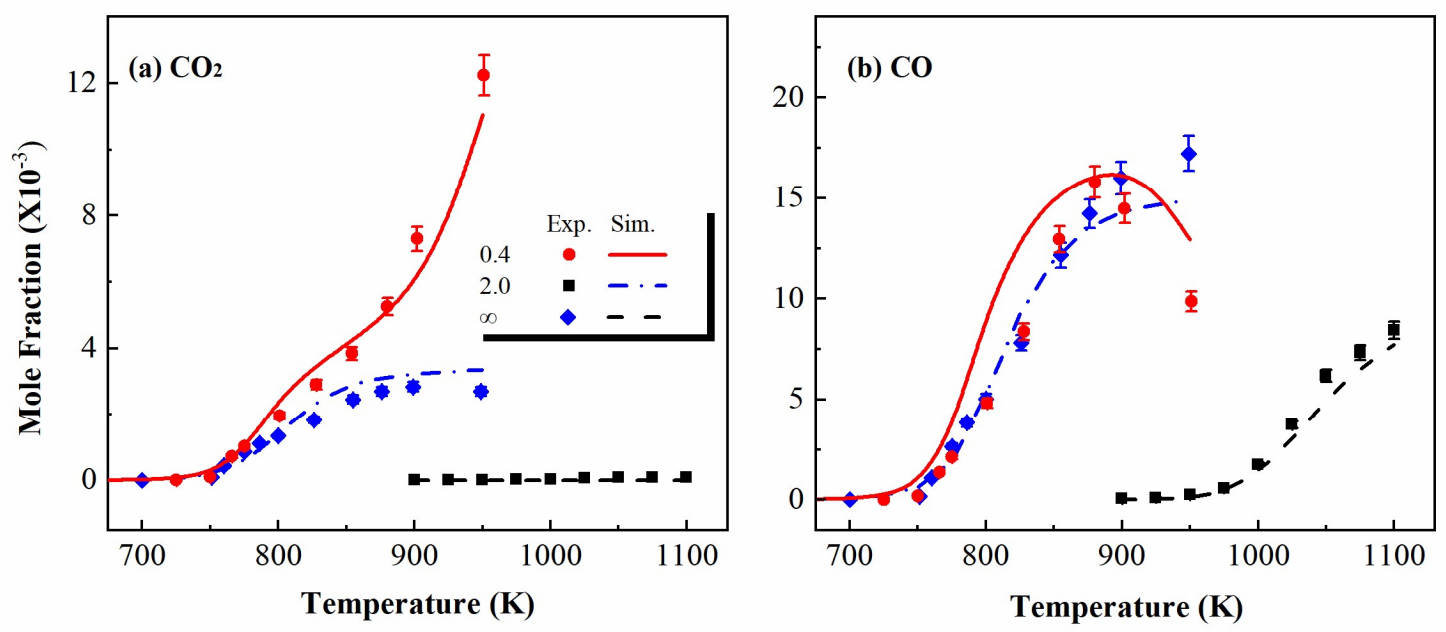

Fig. 6 Measured (symbols) and predicted (curves) mole fraction profiles of $\mathrm{CO}$ (left) and $\mathrm{CO}_{2}$ (right). The oxidation data were measured in this work; the experimental pyrolysis data were taken from Vermeire et al. [25].

\subsection{Light hydrocarbons}

As shown in Fig. 7, the simulated results of light hydrocarbons (methane, ethene, and acetylene as well as $\mathrm{C}_{3} \mathrm{H}_{4}$ (allene plus propyne)), are in general agreement with the measured data. Unsaturated hydrocarbons and oxygenated species are important intermediates during the oxidation and pyrolysis of furfural due to the unsaturated carbon bond. In oxidation, acetylene $\left(\mathrm{C}_{2} \mathrm{H}_{2}\right)$ and ethylene $\left(\mathrm{C}_{2} \mathrm{H}_{4}\right)$ reach their peak values between 850 and $900 \mathrm{~K}$ lagging behind oxygenated intermediates (see Fig. 7), 
such as furan, acrolein, and $\alpha$-pyrone. According to the performed ROP analysis (see section 4.5), the ring-opening of the furan skeleton produces most of the oxygenated intermediates thus being the largest source of light hydrocarbons. For example, furan radicals from $\mathrm{CO}$ elimination of furfural-6 undergo ring opening and isomerization to form the oxygenated radical $\mathrm{CHCHCHCO}$; this molecule then will decompose to acetylene. For pyrolysis (experimental data from Vermeire et al. [25]), the most important light hydrocarbon is found to be $\mathrm{C}_{3} \mathrm{H}_{4}$ - with values being about two times higher than other light hydrocarbons at $1100 \mathrm{~K}$. Based on ROP analysis, $\mathrm{CH}_{2} \mathrm{CHCHCO}$, being generated by $\alpha$-pyrone decomposition, is the main source of $\mathrm{C}_{3} \mathrm{H}_{4}$. Moreover, the acetylene formation pathway results from $\mathrm{C}_{3} \mathrm{H}_{4}$ decomposition, which is different compared to the one identified within furfural oxidation.
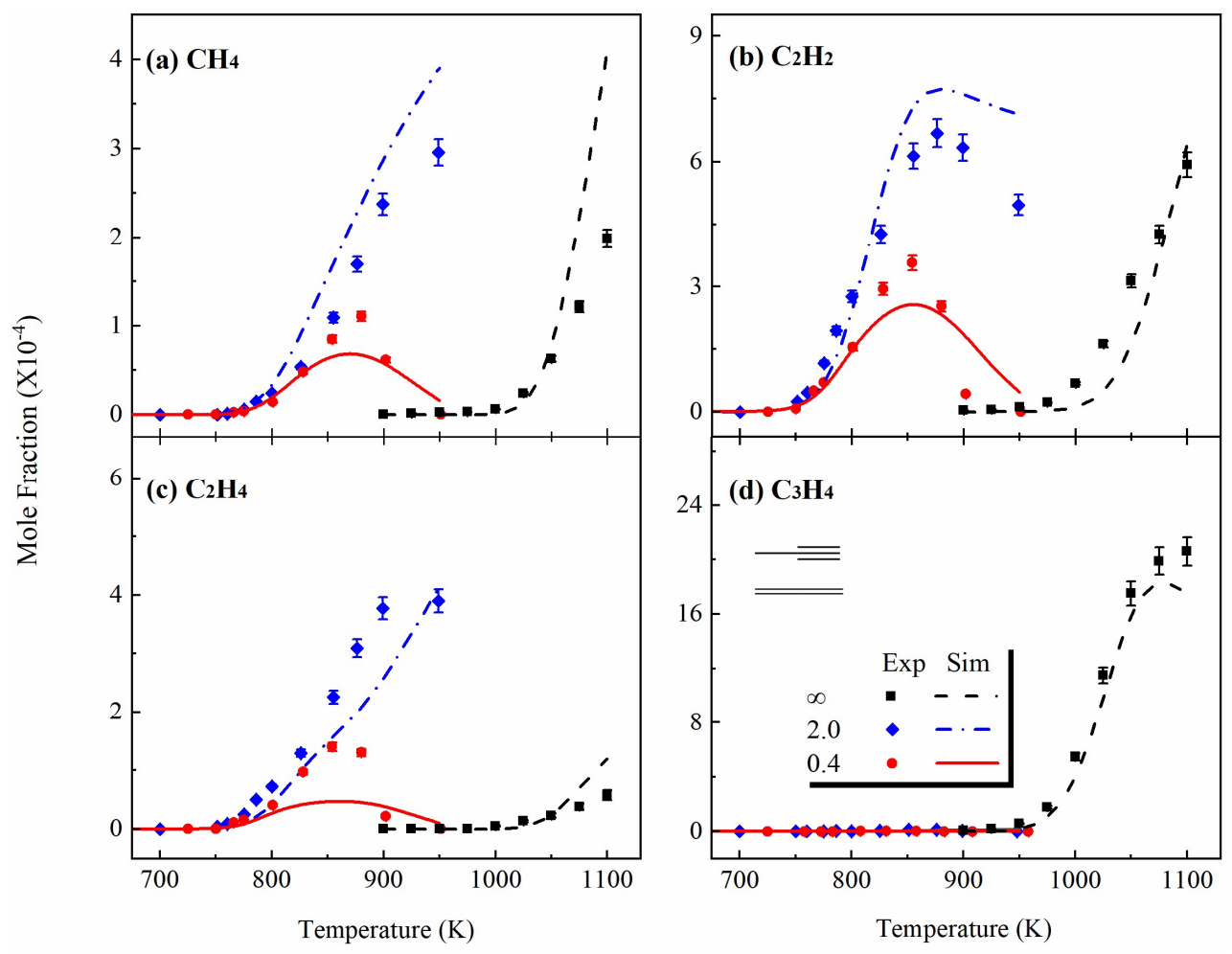

Fig. 7 Measured (symbols) and predicted (curves) mole fraction profiles of light hydrocarbons. The oxidation data were measured in this work; the experimental pyrolysis data were taken from Vermeire et al. [25].

\subsection{Oxygenated intermediates}


Figure 8 shows the experimental and simulated mole fraction profiles of the oxygenated intermediates. Acetaldehyde and acrolein are the most important oxygenated intermediates observed in the oxidation process; however, furan and $\alpha$-pyrone are the main intermediate species within thermal de-

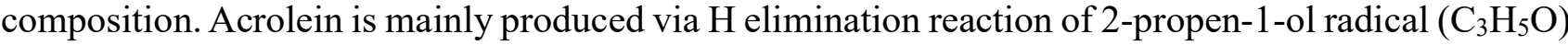
which comes from the decomposition of 2-hydroxyfuran (F2OH); this sequential decomposition pathway can be found in the ROP analysis for oxidation process in 4.5.1. Furan is detected under all experimental conditions, while its formation pathways are different ones. Based on the ROP analysis (see section 4.4), at fuel-lean and fuel-rich conditions (oxidation), furan is mainly produced from the aldehyde group removal of the furfural $2 \mathrm{H}$ radical being formed by the $\mathrm{H}$ addition on the $2 \mathrm{C}$ position of furfural. In pyrolysis studies (experimental data from Vermeire et al. [25]), furfural firstly isomerizes to FVketene, and then a part of FVketene subsequently forms furan via $\mathrm{CO}$ elimination and cyclization isomerization. $\alpha$-Pyrone is the most stable oxygenated intermediate with the highest amount according to the most important sequential reaction: furfural $\rightarrow$ FVketene $\rightarrow \alpha$-pyrone.
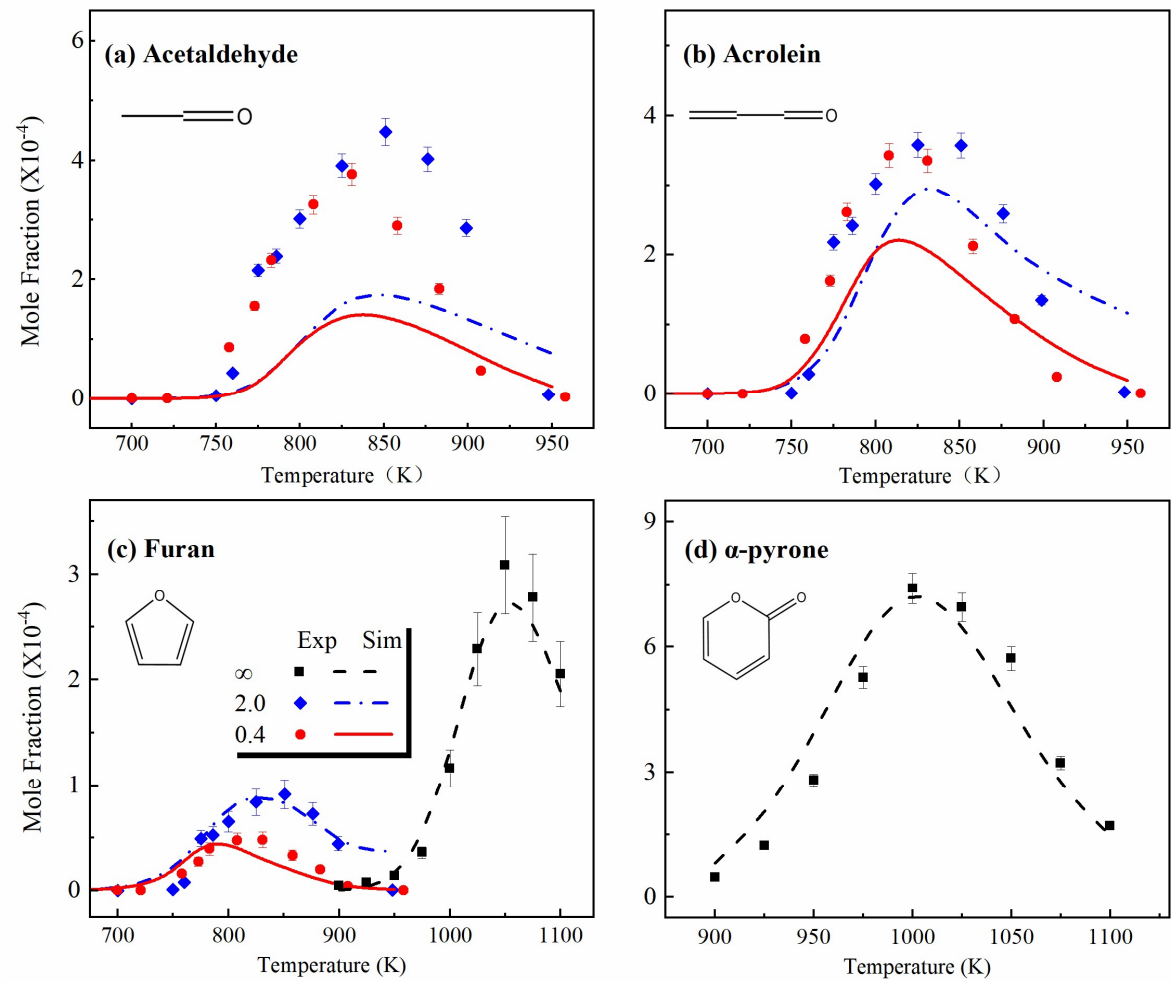

Fig. 8 Measured (symbols) and predicted (curves) mole fraction profiles of oxygenated 
intermediates. The oxidation data were measured in this work; the experimental pyrolysis data were taken from Vermeire et al. [25].

\subsection{ROP and sensitivity analysis for species profiles}

In order to provide a deeper insight into the furfural consumption process at oxidation and pyrolysis conditions, ROP and sensitivity analyses have been performed, at about $50 \%$ fuel consumption ( $800 \mathrm{~K}, 44.0 \%$ conversion at $\Phi=0.4 ; 783 \mathrm{~K}, 52.2 \%$ conversion at $\Phi=2.0 ; 1025 \mathrm{~K}, 58.8 \%$ conversion at $\Phi=\infty)$.

\subsubsection{ROP analysis}

As shown in Fig. 9, the main reaction route of furfural is the dehydrogenation of the aldehyde group leading to furfural-6 radical with $61.4 \%$ (at $\Phi=0.4$ ) and $57.5 \%$ (at $\Phi=2.0$ ) of fuel consumption, respectively. The reaction of furfural-6 decomposing to a furan radical and $\mathrm{CO}$ is the dominant consumption pathway of the furfural-6 radical (98.4\%) at fuel-rich condition. At fuel-lean condition, this reaction takes part in $91.5 \%$ of the furfural-6 radical conversion; $8.4 \%$ of the furfural- 6 radical reacts further with $\mathrm{O}_{2}$ to form the fur-2ylO radical. Addition reactions also play an important role in furfural consumption. At both considered fuel-air ratios, $\mathrm{OH}$ addition at $2 \mathrm{C}$ position producing furfural2OH3J is an important furfural reaction pathway $(21.4 \%, \Phi=2.0 ; 25.0 \%, \Phi=0.4)$. Most of furfural2OH3J then decomposes to $\mathrm{F} 2 \mathrm{OH}$ with $\mathrm{HCO}$ removal. Although F2OH seems to be an important intermediate, it was not detected in the present work, which could be resulted from the detection limitation of the used GC column. $\mathrm{H}$ addition on $2 \mathrm{C}$ and $5 \mathrm{C}$ position takes part in $20.3 \%$ of furfural conversion at $\Phi=2.0$, while the addition reaction consumes around $12.5 \%$ of furfural at $\Phi=0.4$.

For pyrolysis conditions, as Fig. 10 indicates, $\mathrm{H}$ transfer, $\mathrm{H}$ abstraction, and $\mathrm{H}$ addition reactions as well as $\mathrm{CO}$ elimination reactions only account for a small proportion $(0.9 \%)$ to the furfural 
conversion. Almost all furfural is consumed by the ring opening reaction furfural $\leftrightarrow$ FVketene, herein after named as reaction A (see also Fig. 10). Then, 89.8\% of FVketene isomerizes to produce the important intermediate $\alpha$-pyrone, while the rest converts into furan, with $\mathrm{CO}$ removal. According to the potential energy surface for furfural decomposition developed by Vermeire et al. [25], the energy barrier of reaction $\mathrm{A}$ is lower than the one of other radicals formation (carbenes, furfural-6). In Fig. 10, the path with an activation energy closest to the one of reaction A is the path of carbene formations, for example reaction $B$ : furfural $\leftrightarrow F 5$ carbene, with an activation energy only $2 \mathrm{~kJ} / \mathrm{mol}$ higher than the one of reaction A. The formation enthalpy of FVketene is about $190 \mathrm{~kJ} / \mathrm{mol}$ lower than the one of F5carben (at $1000 \mathrm{~K})$, leading to a large difference in the value of Gibbs free energy change $(\triangle \mathrm{G})$, with more than $200 \mathrm{~kJ} / \mathrm{mol}$ between reaction A and B at $1000 \mathrm{~K}$. Moreover, the sequential decomposition pathway of FVketene has also a lower energy barrier and produces more stable products than carbenes. As for $\mathrm{H}$ addition reactions, in the pyrolysis case these reactions have little effect on the consumption of furfural due to the lack of noticeable concentrations of $\mathrm{H}$ radicals. 


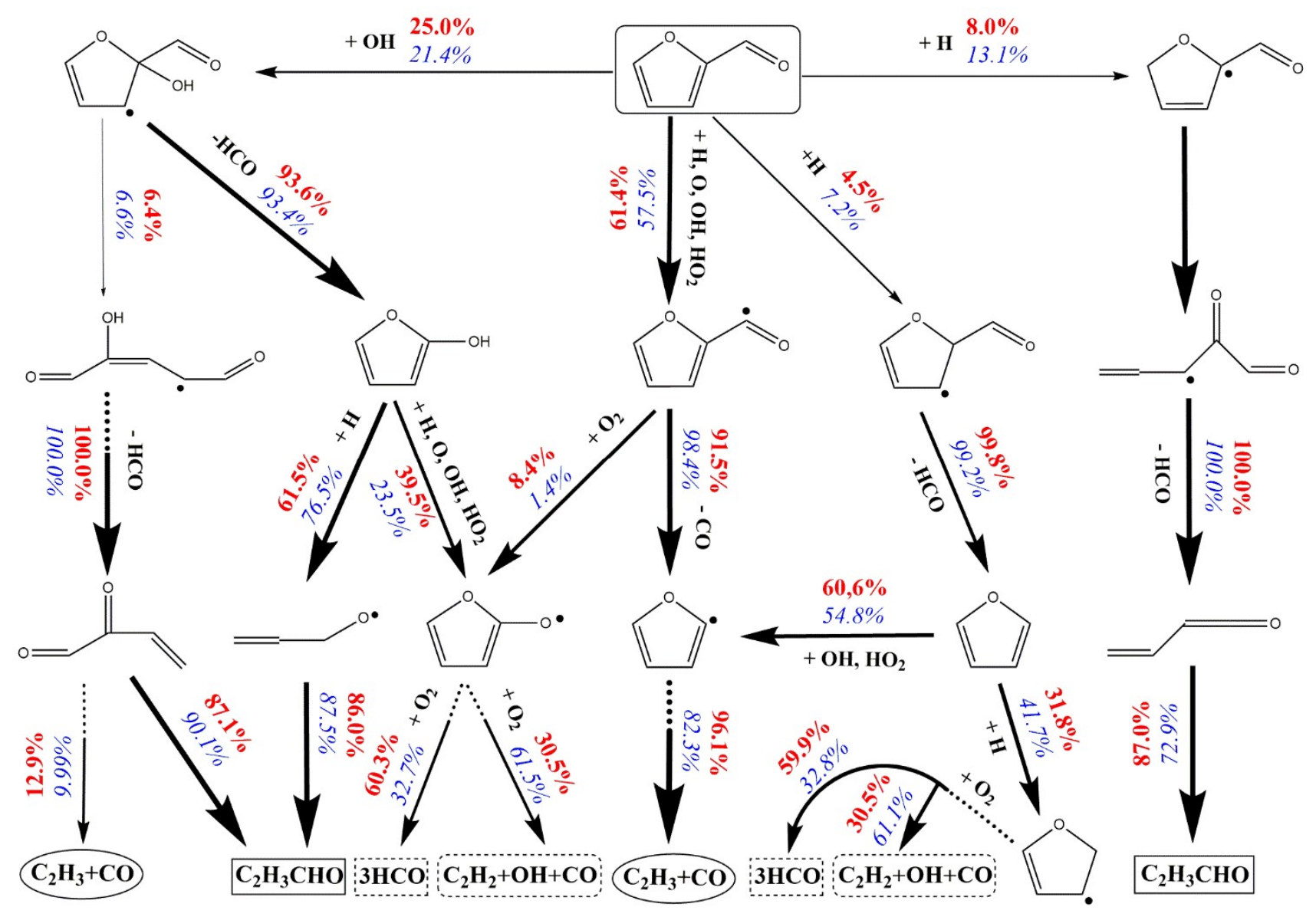

Fig. 9 Rate of production analysis of furfural oxidation: red bold numbers $\Phi=0.4, T=783 \mathrm{~K}$; blue italic numbers $\Phi=2.0, T=800 \mathrm{~K}$.

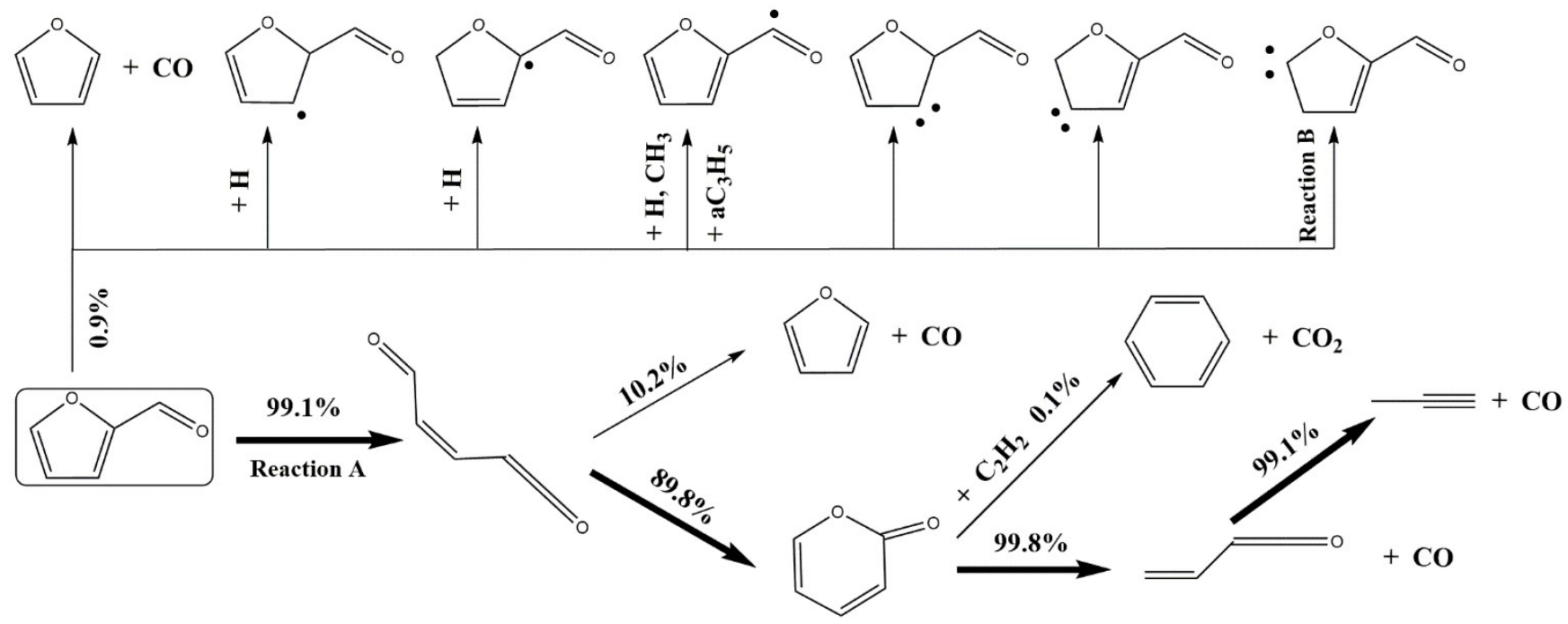

Fig. 10 Rate of production analysis of furfural pyrolysis, calculated for $50 \%$ conversion at 


$$
T=1025 \mathrm{~K} .
$$

\subsubsection{Sensitivity analysis}

Figure 11 shows the sensitivity analysis results of furfural pyrolysis and oxidation. The analysis was performed for the same conditions as the ROP analysis. Firs, the sensitivity analysis for the oxidation is described. It is found that for both conditions, reactions of smaller molecules exhibit the most significant promoting and inhibiting effect. Especially the $\mathrm{C}_{2} \mathrm{H}_{3}$ (vinyl) radical plays an important role in several reactions at lean condition, most probably due to the following reason: $\mathrm{C}_{2} \mathrm{H}_{3}$ is a main product of the dominant furfural consumption pathway according to the ROP analysis; hence, it could be formed in large quantities, and therefore, consequently, its reactions will be of large effect on the overall reaction, depending on the specific conditions,. It is interesting to note that the reaction $\mathrm{C}_{2} \mathrm{H}_{3}+\mathrm{O}_{2}$ has two different pathways showing different effects: (i) $\mathrm{C}_{2} \mathrm{H}_{3}+\mathrm{O}_{2} \leftrightarrow \mathrm{HCHO}+\mathrm{H}+\mathrm{CO}$ with the most inhibiting effect, and (ii) $\mathrm{C}_{2} \mathrm{H}_{3}+\mathrm{O}_{2} \leftrightarrow \mathrm{CH}_{2} \mathrm{CHO}+\mathrm{O}$ with the most promoting effect. The inhibiting effect of the $\mathrm{HCHO}$-path results from the reaction $\mathrm{HCHO}+\mathrm{OH} \leftrightarrow \mathrm{HCO}+\mathrm{H}_{2} \mathrm{O}$ which keeps consuming the important radical $\mathrm{OH}$ within the fuel oxidation, while the $\mathrm{CH}_{2} \mathrm{CHO}$ pathway produces $\mathrm{OH}$ by the reaction $\mathrm{CH}_{2} \mathrm{CHO}+\mathrm{O}_{2} \leftrightarrow \mathrm{HCHO}+\mathrm{CO}+\mathrm{OH}$ leading to the promoting effect. The reaction $\mathrm{H}_{2} \mathrm{O}_{2}$ $(+\mathrm{M}) \leftrightarrow \mathrm{OH}+\mathrm{OH}(+\mathrm{M})$ was also identified to play an important role within the furfural decay because it is the most important $\mathrm{OH}$ formation reaction. Besides the discussed reactions with smaller molecules involved, Fig. 11 included many reactions related directly to the fuel molecule. Especially H abstraction reactions have a positive effect on fuel oxidation. For example, $\mathrm{H}$ abstraction via $\mathrm{OH}$ contributes to about $34.6 \%$ (at $\Phi=2.0$ ) and to $38.7 \%$ (at $\Phi=0.4$ ), respectively of the total furfural consumption. In all reactions related to fuel molecules, only the addition reaction (furfural $+\mathrm{H} \leftrightarrow$ furfural5H) shows a negative effect. This behavior is explained by the fact that the consumption pathway of $\mathrm{CH}_{2} \mathrm{CHCHCO}$ (1,3-butadienal) competes with fuel molecules for free radicals, while $\mathrm{CH}_{2} \mathrm{CHCHCO}$ is an important and stable product of furfural $5 \mathrm{H}$ via the sequential reaction: furfural5H $\leftrightarrow$ 
$\mathrm{CH}_{2} \mathrm{CHCHCOCHO} \leftrightarrow \mathrm{CH}_{2} \mathrm{CHCHCO}+\mathrm{HCO}$. According to the ROP and sensitivity analyses the main furfural oxidation pathway at $50 \%$ conversion as identified in this work is consistent with the investigation of Thorton et al. [23] as mentioned above.

For the purpose of a better visibility of the sensitivity analysis for the pyrolysis, the values of the sensitivity coefficients shown in Fig. 11 are multiplied with a factor 100 except for reaction A. The high sensitivity of reaction A (furfural $\leftrightarrow$ FVketene) results from the nearly total decomposition of furfural leading to a significant positive effect on furfural consumption. The second important promoting reaction for pyrolysis is $\mathrm{H}$ elimination producing furfural-6 radical - its sensitivity factor, even multiplied by 100, is less than the one of reaction A. Fuel consumption has (nearly) no inhibiting effect on pyrolysis. According to their low sensitivity even the most inhibiting reaction $\mathrm{CHCHCHCO}<=>$ $\mathrm{C}_{2} \mathrm{H}_{2}+\mathrm{HCCO}$ is of less importance.

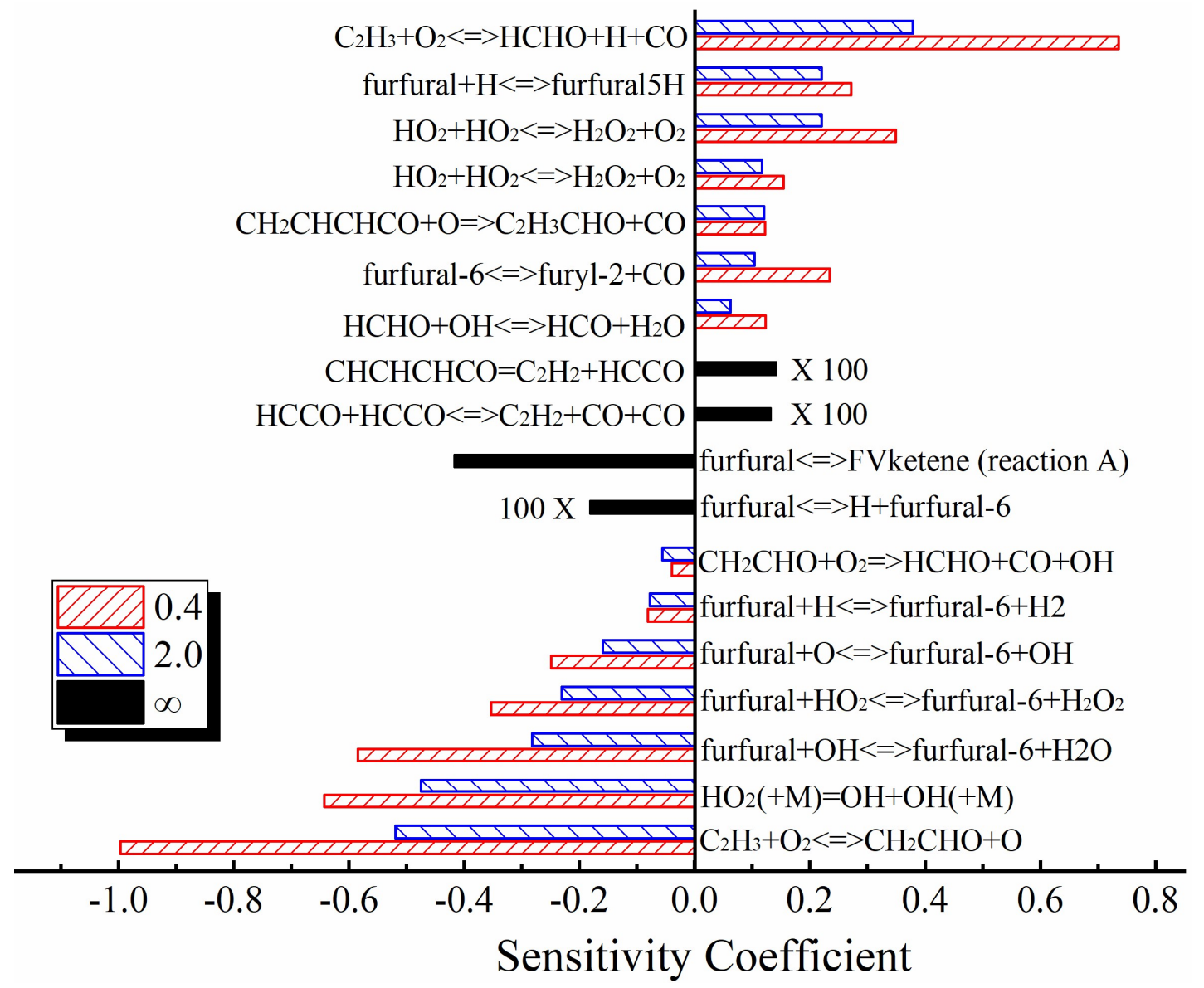

Fig. 11 Sensitivity analysis: Consumption of furfural at 50\% conversion for oxidation: $\Phi=0.4, T=$ 
$783 \mathrm{~K} ; \Phi=2.0, T=800 \mathrm{~K}$; and for pyrolysis: $\Phi=\infty, T=1025 \mathrm{~K}$.

\subsection{Laminar burning velocity of furfural}

The measurement of the laminar burning velocity of furfural as presented in Fig. 12 was performed at 1 bar and $473 \mathrm{~K}$ covering a fuel-air ratio from 0.6 to 1.8 . Located at $\Phi=1.2$, furfural has a very high peak value, about $123 \mathrm{~cm} / \mathrm{s}$, compared to other fuels (see e.g. [36, 37]) with peak values between $70 \mathrm{~cm} / \mathrm{s}$ and $90 \mathrm{~cm} / \mathrm{s}$. The uncertainties in the values are between $2.5 \%$ and $5 \%$, with increasing up to $9 \%$ at the outer fuel-lean and fuel-rich side. When using the reaction model developed within this study for simulating the laminar flame speed, the experimental values are reproduced quite accurately over nearly the whole range of the fuel-air ratio, i.e., between $\Phi=0.8$ and $\Phi=1.8$. Only the modeling of fuel-air mixtures with $\Phi<0.8$ exhibits an increasing overprediction of the measured values. As shown in Fig. 12, the laminar flame speeds have been also calculated using two mechanisms from literature, for the purpose of comparison: from Tran et al. [11] and from the CRECK modeling group [52]. The CRECK model [52] is able to predict the measured burning velocity quite well. In contrast to the simulations using the newly developed model as well as the CRECK model, the experimental data are distinctly overpredicted by the model from Tran et al. [11] which has been primarily developed to simulate species profiles of furan, MF, and DMF: by more than $10 \%$ at its peak value, over nearly the full fuel-air range considered; for $\Phi>1.6$, experimental data are underpredicted. 


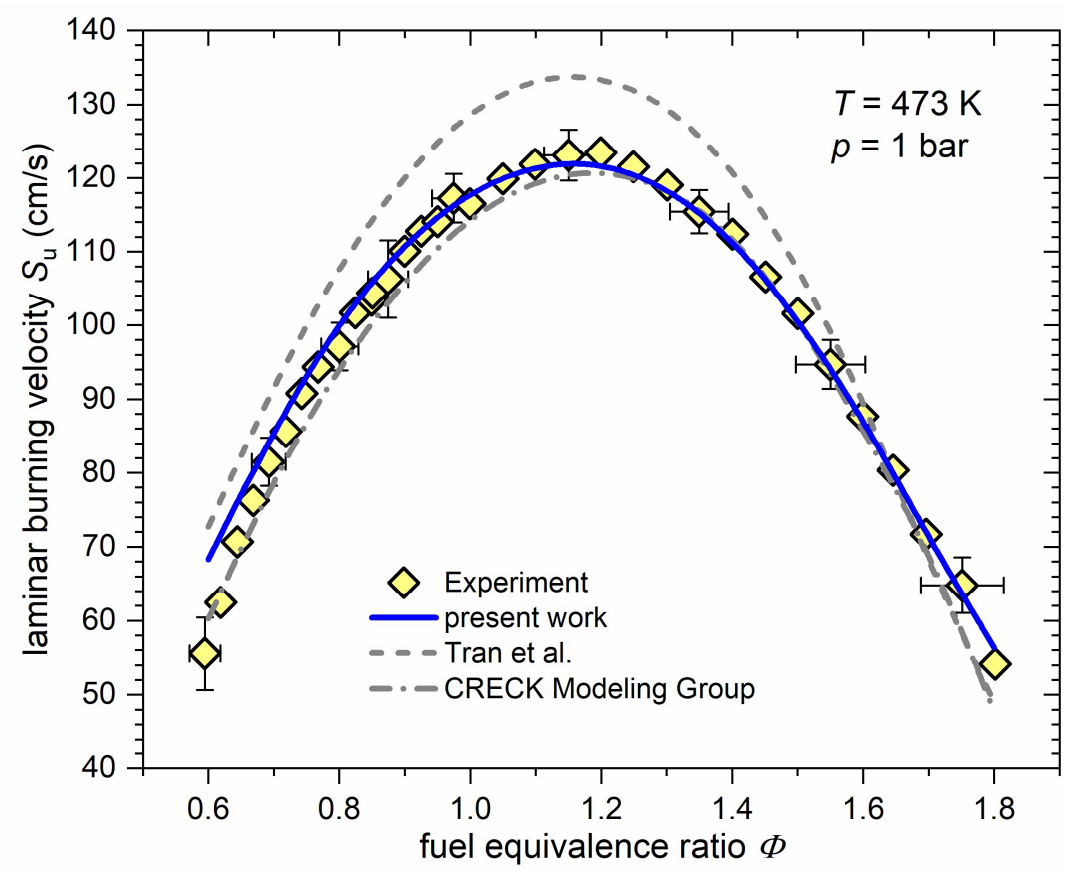

Fig. 12 Results of the measured laminar burning velocity data for atmospheric furfural/air flames compared to calculations (curves) using 3 reaction models: present work (full), Tran et al. [11] (dashed), CRECK Modeling Group [52] (dashed-dotted).

In order to provide further insight into the newly developed mechanism of the present work, a sensitivity analysis for the flame speed calculations at $\Phi=0.9, \Phi=1.2$, and $\Phi=1.6$ was performed. As shown in Fig. 13, the sensitivities for the most important 20 reactions within furfural oxidation indicate that at laminar flame conditions $\mathrm{H}$ abstraction reactions leading to furfural- 6 are the main decomposition reactions of furfural resulting in an acceleration of the furfural oxidation. Here, it is interesting to see that at fuel-rich conditions $(\Phi=1.6)$ the reaction of furfural with $\mathrm{H}$ radicals has a distinct higher sensitivity than with $\mathrm{OH}$ radicals, whereas for $\Phi=1.2$, the sensitivities of these two reactions are very similar. At fuel-lean conditions, reactions with $\mathrm{OH}$ radicals involved become more important due to the high oxygen excess. For the reaction kinetics even more important is the role and contribution of further reactions of furfural-6. The decomposition to furyl-2 accelerates the oxidation process whereas the reaction of furfural- 6 with oxygen leads to a deceleration. However, regarding the 
overall kinetic, $\mathrm{C}_{0}-\mathrm{C}_{2}$ reactions (smaller molecules) are the most important ones since they are leading to chain branching and thus, to the formation of $\mathrm{H}$ and $\mathrm{OH}$ radicals which are among the most dominant radicals within the combustion of hydrocarbons including oxygenated. As expected, the chain branching reaction $\mathrm{H}+\mathrm{O}_{2}<=>\mathrm{O}+\mathrm{OH}$ has the most important effect on the laminar flame speed followed by further reactions yielding first of all $\mathrm{H}$ radicals. On the other hand, recombination reactions consuming $\mathrm{H}$ or $\mathrm{OH}$ radicals lead to a slowdown of the overall oxidation process. Moreover, since the initial generation of $\mathrm{H}$ radicals results from the elimination from fuel molecules, it is typical for flame speed calculations that the absolute sensitivities rise with increasing $\Phi$-values.

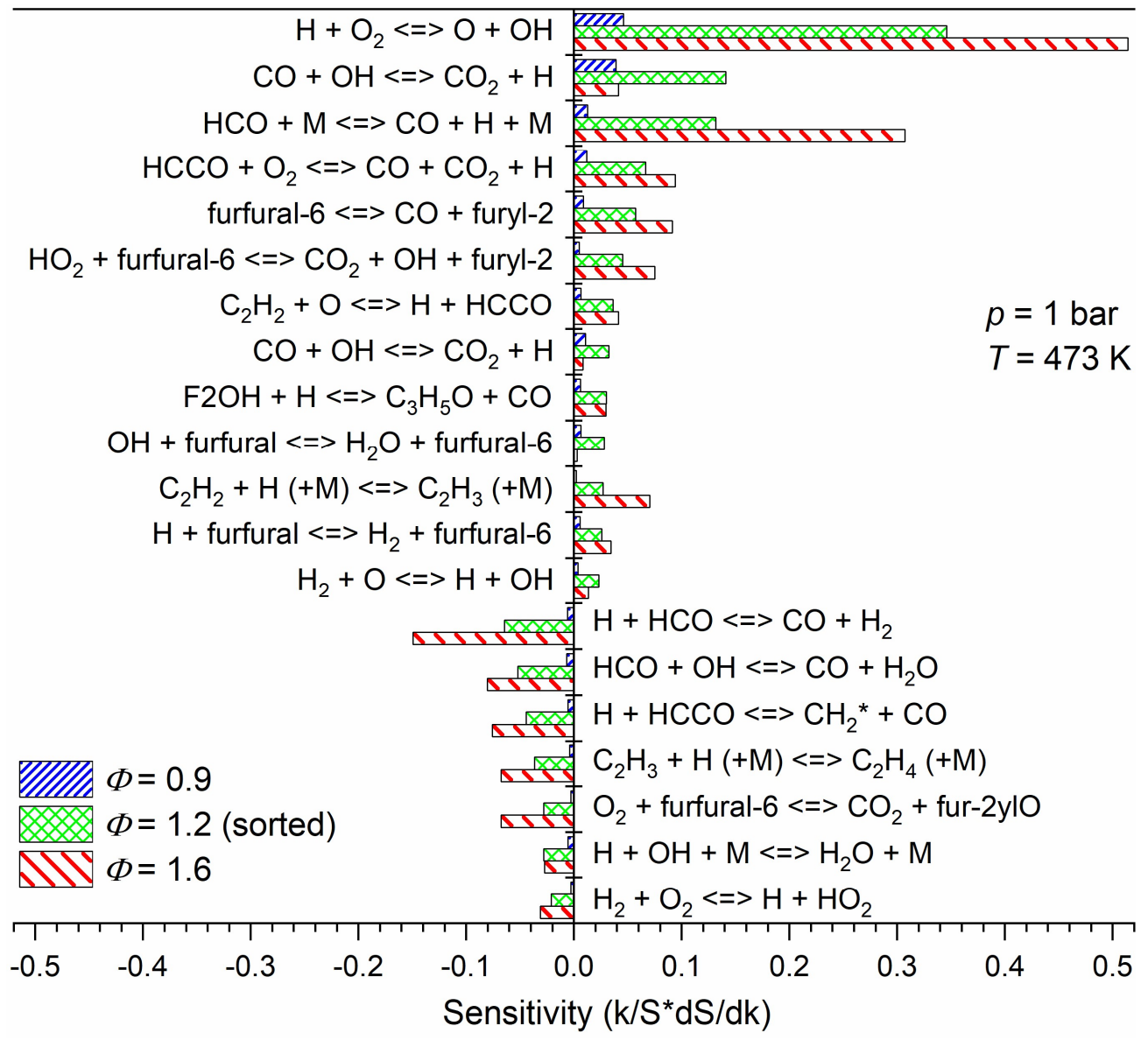

Fig. 13 Sensitivity analysis for laminar flame speed calculations at $\Phi=0.9,1.2$, and 1.6 using the new mechanism developed within the present work. 


\section{Conclusions}

Furfural oxidation was experimentally investigated in a jet stirred reactor at two fuel equivalence ratios ( $\Phi=0.4$ and $\Phi=2.0$ ) over a temperature range of $650-950 \mathrm{~K}$ at atmospheric pressure. It was found that the peak values of light hydrocarbon intermediates and oxygenated intermediates as quantitatively detected and determined by GC increased with decreasing equivalence ratio. Furthermore, the measurement of the laminar burning velocity was performed at ambient pressure (1 bar) and a high preheat temperature $(473 \mathrm{~K})$ covering a fuel-air ratio ranging from 0.6 to 1.8 . The peak of the burning velocity was observed at $\Phi=1.2$ reaching a value of $123 \mathrm{~cm} / \mathrm{s}$. Quantum chemical methods at CBSQB3 level were involved to determine the rate coefficients of the $\mathrm{H}$ abstraction and $\mathrm{H}$ addition as well as of decomposition reactions of furfural. A detailed chemical kinetic reaction model containing 382 species and 2262 reactions was developed to predict in particular the furfural oxidation for species profiles measured in the JSR and for the laminar burning velocity but also the furfural pyrolysis by exploiting species data published in literature. In general, satisfying agreement between prediction and measurement was found. According to ROP and sensitivity analyses, for oxidation conditions, $\mathrm{H}$ abstraction at the aldehyde group of furfural consumes about $60 \%$ of furfural, with $\mathrm{OH}$ as well as $\mathrm{H}$ addition reactions also playing important roles in furfural consumption. For pyrolysis, the decomposition of furfural produces formylvinylketene identified to be the dominant pyrolysis consumption pathway. The results, in terms of the experimental data base provided and of the detailed chemical kinetic model newly developed, and the findings obtained within the present study are considered as an important contribution to achieve a more detailed understanding of the combustion behavior of furfural and of furan derivatives as well. 


\section{Acknowledgement}

The authors thank for financial support from the National Natural Science Foundation of China (Nr. 51976216/51888103), the Ministry of Science and Technology of China (2017YFA0402800), and the Recruitment Program of Global Youth Experts. The support from the Alexander-von-Humboldt Research Group Linkage Program is gratefully acknowledged.

\section{References}

[1] Z. Chen, L. Wang, K. Zeng, A comparative study on the combustion and emissions of dual-fuel engine fueled with natural gas/methanol, natural gas/ethanol, and natural gas/n-butanol, Energy Conversion and Management 192 (2019) 11-19.

[2] M.Z. Iş1k, H. Aydın, Analysis of ethanol RCCI application with safflower biodiesel blends in a high load diesel power generator, Fuel 184 (2016) 248-260.

[3] G. Chen, Y. Shen, Q. Zhang, M. Yao, Z. Zheng, H. Liu, Experimental study on combustion and emission characteristics of a diesel engine fueled with 2, 5-dimethylfuran-diesel, n-butanol-diesel and gasoline-diesel blends, Energy 54 (2013) 333-342.

[4] N. Xu, J. Gong, Z. Huang, Review on the production methods and fundamental combustion characteristics of furan derivatives, Renewable and Sustainable Energy Reviews 54 (2016) 1189-1211. [5] H. Liu, J. Xu, Z. Zheng, S. Li, M. Yao, Effects of fuel properties on combustion and emissions under both conventional and low temperature combustion mode fueling 2, 5-dimethylfuran/diesel blends, Energy 62 (2013) 215-223.

[6] H. Xiao, X. Yang, B. Hou, R. Wang, Q. Xue, H. Ju, Combustion performance and pollutant emissions analysis of a diesel engine fueled with biodiesel and its blend with 2-methylfuran, Fuel 237 (2019) 1050-1056.

[7] H. Xiao, R. Wang, P. Zeng, A. Jiang, B. Hou, S. Yang, Particulate matter and unregulated emissions of diesel engine fueled with 2-methylfuran diesel blends, Fuel 208 (2017) 168-173.

[8] M. Eldeeb, B. Akih-Kumgeh, Recent trends in the production, combustion and modeling of furanbased fuels, Energies 11 (2018) 512.

[9] A. Sudholt, L. Cai, J. Heyne, F.M. Haas, H. Pitsch, F.L. Dryer, Ignition characteristics of a bioderived class of saturated and unsaturated furans for engine applications, Proceedings of the Combustion Institute 35 (2015) 2957-2965.

[10] Y. Luo, Z. Li, X. Li, X. Liu, J. Fan, J.H. Clark, C. Hu, The production of furfural directly from hemicellulose in lignocellulosic biomass: A review, Catalysis Today 319 (2019) 14-24.

[11] L.S. Tran, Z. Wang, H.H. Carstensen, C. Hemken, F. Battin-Leclerc, K. Kohse-Höinghaus, Comparative experimental and modeling study of the low-to moderate-temperature oxidation chemistry of 2, 5-dimethylfuran, 2-methylfuran, and furan, Combustion and Flame 181 (2017) 251269. 
[12] J. Julis, W. Leitner, Synthesis of 1-octanol and 1, 1-dioctyl ether from biomass-derived platform chemicals, Angewandte Chemie International Edition 51 (2012) 8615-8619.

[13] W. Leitner, J. Klankermayer, S. Pischinger, H. Pitsch, K. Kohse-Höinghaus, Advanced biofuels and beyond: chemistry solutions for propulsion and production, Angewandte Chemie International Edition 56 (2017) 5412-5452.

[14] J.P. Lange, E. Van Der Heide, J. van Buijtenen, R. Price, Furfural a promising platform for lignocellulosic biofuels, ChemSusChem 5 (2012) 150-166.

[15] J.M. Wilson, M.T. Baeza-Romero, J.M. Jones, M. Pourkashanian, A. Williams, A.R. Lea-Langton, A.B. Ross, K.D. Bartle, Soot formation from the combustion of biomass pyrolysis products and a hydrocarbon fuel, n-decane: an aerosol time of flight mass spectrometer (ATOFMS) study, Energy \& Fuels 27 (2013) 1668-1678.

[16] S. Wu, D. Kang, H. Zhang, R. Xiao, A.L. Boehman, The oxidation characteristics of furan derivatives and binary TPGME blends under engine relevant conditions, Proceedings of the Combustion Institute 37 (2018) 4635-4643.

[17] S. Wang, G. Dai, H. Yang, Z. Luo, Lignocellulosic biomass pyrolysis mechanism: A state-of-theart review, Progress in Energy \& Combustion Science 62 (2017) 33-86.

[18] P.R. Patwardhan, R.C. Brown, B.H. Shanks, Product Distribution from the Fast Pyrolysis of Hemicellulose, Chemsuschem 4 (2011).

[19] Z. Li, C. Liu, X. Xu, Q. Li, A theoretical study on the mechanism of xylobiose during pyrolysis process, Computational \& Theoretical Chemistry 1117 (2017) 130-140.

[20] J.Q. Bond, D.M. Alonso, D. Wang, R.M. West, J.A. Dumesic, Integrated Catalytic Conversion of $\gamma$-Valerolactone to Liquid Alkenes for Transportation Fuels, Science 327 (2010) p.1110-1114.

[21] A. Corma, O. de la Torre, M. Renz, N. Villandier, Production of High-Quality Diesel from Biomass Waste Products, Angewandte Chemie-International Edition 50 (2011) 2375-2378.

[22] X. Zhao, L. Wang, Atmospheric oxidation mechanism of furfural initiated by hydroxyl radicals, The Journal of Physical Chemistry A 121 (2017) 3247-3253.

[23] M.M. Thorton, P.C. Malte, A.L. Crittenden, Oxidation of furan and furfural in a well-stirred reactor, Symposium (International) on Combustion 21 (1988) 979-989.

[24] A.K. Vasiliou, J.H. Kim, T.K. Ormond, K.M. Piech, K.N. Urness, A.M. Scheer, D.J. Robichaud, C. Mukarakate, M.R. Nimlos, J.W. Daily, Q. Guan, H.H. Carstensen, G.B. Ellison, Biomass pyrolysis: thermal decomposition mechanisms of furfural and benzaldehyde, The Journal of chemical physics 139 (2013) 104310.

[25] F.H. Vermeire, H.H. Carstensen, O. Herbinet, F. Battin-Leclerc, G.B. Marin, K.M. Van Geem, The thermal decomposition of furfural: molecular chemistry unraveled, Proceedings of the Combustion Institute 37 (2018) 445-452.

[26] Y. Li, Q. Meng, J. Wang, Y. Zhang, C. Cao, Z. Cheng, J. Yang, F. Liu, L. Zhang, Y. Pan, Experimental and theoretical investigation of the pyrolysis of furfural, The Journal of Physical Chemistry A 123 (2018) 103-110.

[27] C.D. Hurd, A. Goldsby, E. Osborne, Furan reactions. II. furan from furfural, Journal of the American Chemical Society 54 (1932) 2532-2536.

[28] M. Grela, A. Colussi, Kinetics and mechanism of the thermal decomposition of unsaturated aldehydes: benzaldehyde, 2-butenal, and 2-furaldehyde, The Journal of Physical Chemistry 90 (1986) 434-437. 
[29] K.P. Somers, J.M. Simmie, W.K. Metcalfe, H.J. Curran, The pyrolysis of 2-methylfuran: a quantum chemical, statistical rate theory and kinetic modelling study, Physical Chemistry Chemical Physics 16 (2014) 5349-5367.

[30] K.P. Somers, J.M. Simmie, F. Gillespie, C. Conroy, G. Black, W.K. Metcalfe, F. Battin-Leclerc, P. Dirrenberger, O. Herbinet, P.A. Glaude, P. Dagaut, C. Togbé, K. Yasunaga, R.X. Fernandes, C. Lee, R. Tripathi, H.J. Curran, A comprehensive experimental and detailed chemical kinetic modelling study of 2,5-dimethylfuran pyrolysis and oxidation, Combustion and Flame 160 (2013) 2291-2318.

[31] L. Zhou, D. Yu, Z. Wang, L.J. Cheng, Z.H. Jin, J.J. Weng, J.Z. Yang, Z.Y. Tian, A detailed kinetic study on oxidation of benzyl alcohol, Combustion and Flame 207 (2019) 10-19.

[32] Y.X. Liu, S. Richter, C. Naumann, M. Braun-Unkhoff, Z.Y. Tian, Combustion study of a surrogate jet fuel, Combustion and Flame 202 (2019) 252-261.

[33] J.J. Weng, Y.X. Liu, B.Y. Wang, L.L. Xing, L.D. Zhang, Z.Y. Tian, Experimental and kinetic investigation of 1,2,4-trimethylbenzene oxidation at low temperature, Proceedings of the Combustion Institute 36 (2017) 909-917.

[34] B.Y. Wang, Y.X. Liu, J.J. Weng, P. Glarborg, Z.Y. Tian, New insights in the low-temperature oxidation of acetylene, Proceedings of the Combustion Institute 36 (2017) 355-363.

[35] J.T. Scanlon, D.E. Willis, Calculation of flame ionization detector relative response factors using the effective carbon number concept, Journal of Chromatographic Science 23 (1985) 333-340.

[36] S. Richter, T. Kathrotia, C. Naumann, T. Kick, N. Slavinskaya, M. Braun-Unkhoff, U. Riedel, Experimental and modeling study of farnesane, Fuel 215 (2018) 22-29.

[37] T. Kick, J. Herbst, T. Kathrotia, J. Marquetand, M. Braun-Unkhoff, C. Naumann, U. Riedel, An experimental and modeling study of burning velocities of possible future synthetic jet fuels, Energy 43 (2012) 111-123.

[38] G. Andrews, D. Bradley, Determination of burning velocities: a critical review, Combustion and Flame 18 (1972) 133-153.

[39] H. Eberius, T. Kick, Stabilization of premixed, conical methane flames at high pressure, Berichte der Bunsengesellschaft für physikalische Chemie 96 (1992) 1416-1419.

[40] Chemkin-Pro 15092, Reaction Design: San Diego, 2009.

[41] D.G. Goodwin, H.K. Moffat, R.L. Speth, Cantera: An object-oriented software toolkit for chemical kinetics, thermodynamics, and transport processes, http://www.cantera.org, version 2.2. 1, (2016).

[42] Y.X. Liu, B.Y. Wang, J.J. Weng, D. Yu, S. Richter, T. Kick, C. Naumann, M. Braun-Unkhoff, Z.Y. Tian, A wide-range experimental and modeling study of oxidation and combustion of $n-$ propylbenzene, Combustion and Flame 191 (2018) 53-65.

[43] M. Pelucchi, S. Namysl, E. Ranzi, A. Frassoldati, O. Herbinet, F. Battin-Leclerc, T. Faravelli, An experimental and kinetic modelling study of n-C4C6 aldehydes oxidation in a jet-stirred reactor, Proceedings of the Combustion Institute 37 (2018) 389-397.

[44] Z. Tian, T. Yuan, R. Fournet, P.A. Glaude, B. Sirjean, F. Battin-Leclerc, K. Zhang, F. Qi, An experimental and kinetic investigation of premixed furan/oxygen/argon flames, Combustion and Flame 158 (2011) 756-773.

[45] M. Pelucchi, C. Cavallotti, A. Cuoci, T. Faravelli, A. Frassoldati, E. Ranzi, Detailed kinetics of substituted phenolic species in pyrolysis bio-oils, Reaction Chemistry \& Engineering 4 (2019) 490506 . 
[46] D. Liu, C. Togbé, L.S. Tran, D. Felsmann, P. Oßwald, P. Nau, J. Koppmann, A. Lackner, P.-A. Glaude, B. Sirjean, R. Fournet, F. Battin-Leclerc, K. Kohse-Höinghaus, Combustion chemistry and flame structure of furan group biofuels using molecular-beam mass spectrometry and gas chromatography - Part I: Furan, Combustion and Flame 161 (2014) 748-765.

[47] M.J. Frisch, e. al., Gaussian16, Revision A.03, Gaussian, Inc., Wallingford, CT, 2016.

[48] Q. Zhao, Y. Zhang, F. Zhang, Z. Huang, Pressure-dependent kinetics on benzoyl radical+ O2 and its implications for low temperature oxidation of benzaldehyde, Combustion and Flame 214 (2020) 139-151.

[49] K.P. Somers, J.M. Simmie, F. Gillespie, U. Burke, J. Connolly, W.K. Metcalfe, F. Battin-Leclerc, P. Dirrenberger, O. Herbinet, P.A. Glaude, H.J. Curran, A high temperature and atmospheric pressure experimental and detailed chemical kinetic modelling study of 2-methyl furan oxidation, Proceedings of the Combustion Institute 34 (2013) 225-232.

[50] V.B. Mokrushin, V. Bedanov, W. Tsang, et al., ChemRate, version 1.5.8 ed., National Institute of Standards and Testing, Gaithersburg, MD, 2009.

[51] L.S. Tran, B. Sirjean, P.A. Glaude, K. Kohse-Höinghaus, F. Battin-Leclerc, Influence of substituted furans on the formation of Polycyclic Aromatic Hydrocarbons in flames, 35 (2015) 17351743.

[52] The CRECK Modeling Group, Complete mechanism (Version 1412, December 2014), http://creckmodeling.chem.polimi.it/menu-kinetics/menu-kinetics-detailed-mechanisms/menukinetics-complete-mechanism (access $25^{\text {th }}$ October 2019).

[53] Z. Cheng, S. He, L. Xing, L. Wei, W. Li, T. Li, B. Yan, W. Ma, G. Chen, Experimental and Kinetic Modeling Study of 2-Methylfuran Pyrolysis at Low and Atmospheric Pressures, Energy \& Fuels 31 (2017) 896-903. 